\title{
HAM/TSP-derived HTLV-1-infected T cell lines promote morphological and functional changes in human astrocytes cell lines: possible role in the enhanced $T$ cells recruitment into Central Nervous System
}

Eduardo Samo Gudo ${ }^{1,2^{*}}$, Suse Dayse Silva-Barbosa ${ }^{3}$, Leandra Linhares-Lacerda², Marcelo Ribeiro-Alves², Suzana Corte Real ${ }^{4}$, Dumith Chequer Bou-Habib ${ }^{2}$ and Wilson Savino ${ }^{2}$

\begin{abstract}
Background: The mechanisms through which HTLV-1 leads to and maintains damage in the central nervous system of patients undergoing HTLV-1 associated myelopathy/tropical spastic paraparesis (HAM/TSP) are still poorly understood. In recent years, increasing evidence indicates that, not only lymphocytes but also glial cells, in particular astrocytes, play a role in the pathophysiology of HAM/TSP. In this study we used a model of co-culture between human HTLV-1-infected (CIB and C91PL) and non-infected (CEM) T lymphocyte cell lines and astrocyte (U251 and U87) cell lines to mimic the in vivo $T$ cell-astrocyte interactions.

Results: We first observed that CIB and C91PL adhere strongly to cultured astrocytes cell lines, and that co-cultures of HTLV-1 infected and astrocyte cell lines cells resulted in rapid syncytium formation, accompanied by severe morphological alterations and increased apoptotic cell death of astrocyte cells. Additionally, cultures of astrocyte cell lines in presence of supernatants harvested from HTLV-1-infected T cell cultures resulted in significant increase in the mRNA of CCL2, CXCL1, CXCL2, CXCL3, CXCL10, IL-13, IL-8, NFKB1, TLR4, TNF, MMP8 and VCAM1, as compared with the values obtained when we applied supernatants of non-infected T- cell lines. Lastly, soluble factors secreted by cultured astrocytic cell lines primed through 1-h interaction with infected T cell lines, further enhanced migratory responses, as compared to the effect seen when supernatants from astrocytic cell lines were primed with non-infected T cell lines.

Conclusion: Collectively, our results show that HTLV-1 infected T lymphocyte cell lines interact strongly with astrocyte cell lines, leading to astrocyte damage and increased secretion of attracting cytokines, which in turn may participate in the further attraction of HTLV-1-infected T cells into central nervous system (CNS), thus amplifying and prolonging the immune damage of CNS.
\end{abstract}

Keywords: Astrocytes, HTLV-1-infected lymphocytes, Extracellular matrix, Chemokines, Integrins

\footnotetext{
* Correspondence: esamogudoj@@gmail.com

${ }^{1}$ National Institute of Health, Ministry of Health, Av. Eduardo Mondlane, 1008

Maputo, Mozambique

${ }^{2}$ Laboratory on Thymus Research, Oswaldo Cruz Institute, Oswaldo Cruz

Foundation, Rio de Janeiro, Brazil

Full list of author information is available at the end of the article
}

C Biomed Central

(c) 2015 Gudo et al. Open Access This article is distributed under the terms of the Creative Commons Attribution 4.0 International License (http://creativecommons.org/licenses/by/4.0/), which permits unrestricted use, distribution, and reproduction in any medium, provided you give appropriate credit to the original author(s) and the source, provide a link to the Creative Commons license, and indicate if changes were made. The Creative Commons Public Domain Dedication waiver (http://creativecommons.org/publicdomain/zero/1.0/) applies to the data made available in this article, unless otherwise stated. 


\section{Background}

Human T-cell leukemia virus type 1 (HTLV-1) is the etiological agent of HTLV-1-associated myelopathy/tropical spastic paraparesis (HAM/TSP), a chronic and slowly progressive neurodegenerative disease of the central nervous system (CNS) [1, 2] and Adult T-cell leukemia/lymphoma (ATL) [3]. Worldwide, an estimated 20 million people are infected with HTLV-1, thus placing this infection as a serious public health problem. Nevertheless, the majority of infected individuals remain asymptomatic carriers and less than $5 \%$ develop HAM/TSP [4-8].

Histopathological findings of CNS revealed that HAM/ TSP affects mostly the lower and middle thoracic spinal cord, with marked degeneration of the corticospinal tracts and demyelination, accompanied by diffuse and symmetrical degeneration of the anterolateral and inner portion of the posterior columns [9]. These findings are consistent with the HAM/TSP patient's neurological symptoms, including spastic paraplegia of the lower extremities, loss of bladder control, and sexual dysfunction [1, 10-12].

To date, the precise mechanisms by which HTLV-1 promotes these lesions remain poorly understood. Nevertheless, available data indicate that progression to $\mathrm{HAM} / \mathrm{TSP}$ is characterized by presence of an exaggerated and chronic immune response [13], accompanied by massive infiltration of mononuclear cells into the CNS, hyper secretion of pro-inflammatory cytokines and chemokines [14] and spontaneous proliferation $\mathrm{T}$ lymphocytes [13-24]. Although the lesions in the CNS have been primarily attributed to these infiltrating lymphocytes, growing evidence points that glial cells, particularly astrocytes, play a key role in this process [14, 25]. Damage of astrocytes is structurally and functionally deleterious to the CNS, since these cells exert important functions, such as: maintenance of the integrity of the blood-brain barrier (BBB), neural cell survival and control of brain excitability [26-28]. Histopathological findings from post mortem tissues revealed that astrocytes from HAM/TSP lesions bear an activated phenotype and produce high amounts of pro-inflammatory cytokines, matrix metalloproteinases (MMPs) and chemokines [14, 29, 30]. Additionally, in vitro studies demonstrated that interactions with HTLV-1-infected lymphocytes resulted in morphological changes of astrocytes similarly to those found in post mortem [31, 32], being accompanied by metabolic deregulation $[33,34]$.

However the participation of astrocytes in the pathophysiology of HAM/TSP remains poorly understood, particularly their role in the recruitment and trafficking of peripheral T cells into CNS. In this context, we conducted a study to investigate the morphological and functional alterations exerted by HTLV-1-infected T cell lines upon astrocytoma-derived cell lines. In particular, we used an in vitro model of $\mathrm{T}$ cell-astrocyte cell lines interaction to approach the potential the impact of HTLV1 -infected $\mathrm{T}$ cell lines in the integrity and gene expressing profile of migration-related genes of astrocytic cell lines. We also analyzed the migratory response of HTLV-1-T lymphocyte cell lines under the stimulation of astrocytic cell lines primed with supernatants derived from HTLV $-1^{+} \mathrm{T}$ cell lines. Our results indicate that under transient interactions with HTLV-1-infected T cell line cells, astrocytic cell lines undergo major morphological changes, together with modulation in the expression of a variety of cell-migration genes. In turn, such reactive astrocytic cell lines increase migratory responses of HTLV-1-infected lymphocytes, thus suggesting a role of these glial elements in the recruitment of additional $\mathrm{T}$ cells into CNS.

\section{Results}

Increased adhesion of HTLV-1-infected T lymphocyte cell lines onto astrocytoma cell lines

In the first set of experiments, we investigated the adhesion of HTLV-1-infected (CIB and C91PL) and noninfected (CEM) $\mathrm{T}$ cell lines to astrocytoma monolayers (U251). The adhesion assay was performed during $30 \mathrm{~min}$, after which non-adherent lymphocytes cell lines were removed and adherent lymphocytes cell lines counted after Giemsa staining. We found that after $30 \mathrm{~min}$ in cocultures, the adhesion degree of HTLV-1 infected T cell lines, (CIB in the Fig. 1b and C91PL in the Fig. 1c) to the astrocytoma cell lines was significantly higher than that of uninfected $\mathrm{T}$ cell lines, as illustrated by the measurement of adhesion index of CIB cells (Fig. 1d).

\section{Co-culture of HTLV-1-T lymphocyte cell lines with astrocytic cell lines results in rapid syncytium formation}

Since HTLV-1 infected T cell lines adhered strongly to the astrocytoma monolayers, we investigated the morphological alterations, including syncytium formation after persistent interaction between these cells. For this purpose, HTLV-1 infected T cell lines (CIB and C91PL) were co-cultured with the astrocytoma cell lines (U251 and U87) for up to $20 \mathrm{~h}$, after which, non-adherent cells were removed and the alterations observed after Giemsa staining. We observed heterocellular cell fusion, and syncytium formation between HTLV-1 infected T cell lines and astrocytoma cell lines as early as $6 \mathrm{~h}$ post coculture. These changes were equally seen when the CIB (Fig. 2b, c, f, g) and C91PL (Fig. 2d) HTLV-1 infected cell lines were added onto the astrocytic monolayer. In addition, the effect of HTLV-1 infected cell lines on the astrocytoma cell lines U251 (Fig. 2a-d) and U87 (Fig. 2e-g) was similar. No syncytium could be detected when CEM cells were co-cultured with either astrocytoma monolayer (Fig. 2a, e) or when non astrocytic cell 


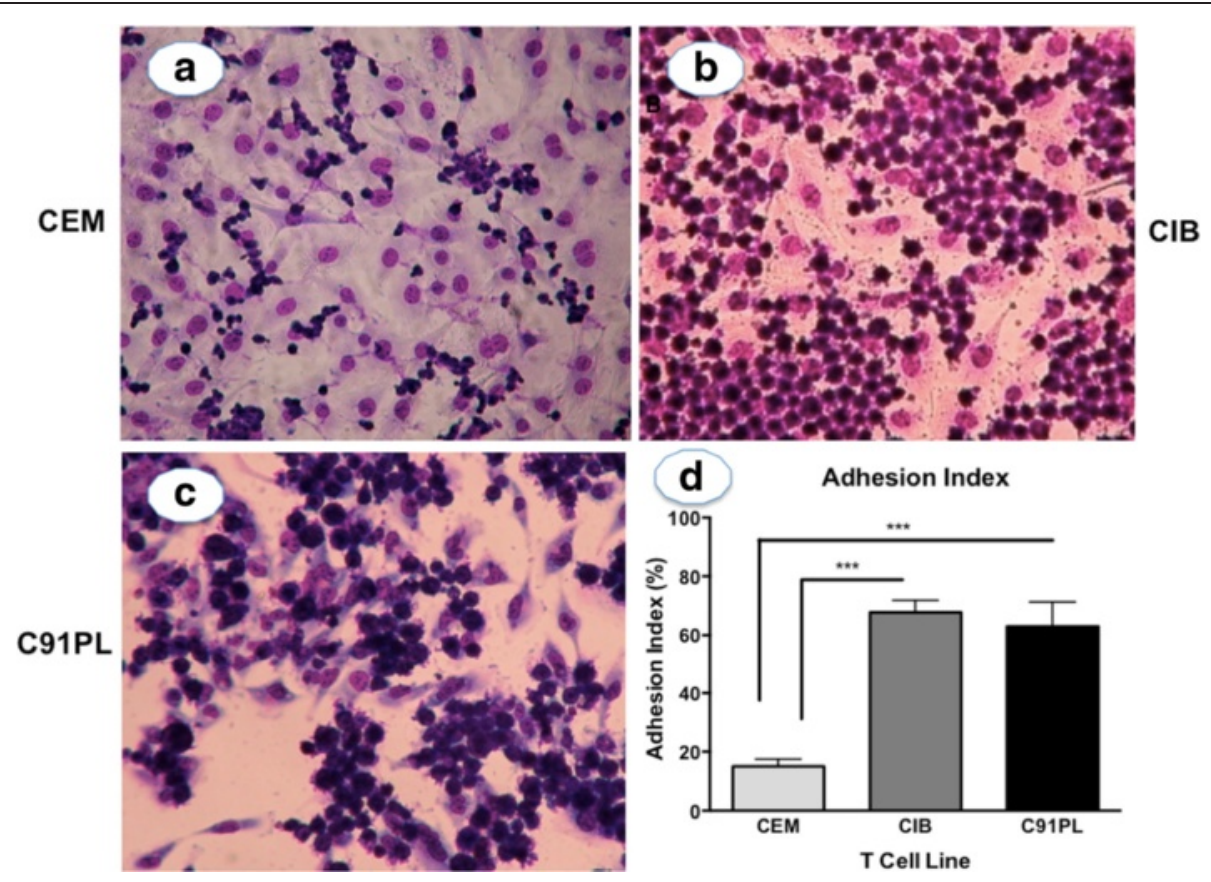

Fig. 1 Enhanced adhesion of HTLV-1-infected T cell lines onto human astrocytoma cell lines. HTLV-1-infected (CIB and C91PL) or non-infected (CEM) T cell lines were co-cultured with astrocytoma cell lines (U251) for 30 min. Representative microscopic fields of low magnification indicate higher adhesion degree of HTLV-1-infected T cell lines ( $\mathbf{b}$ and $\mathbf{c}$ ) versus non-infected T cell lines (a). Panel d depicts higher adhesion degree of HTLV-1-infected T cell lines (CIB and C91PL) as determined by the measurement of adhesion index. Values in panel (d) correspond to mean \pm se of 3 independent experiments for each $T$ cell line. ${ }^{*} p<0.05$. Original magnifications: $\times 200$

lines (Hela cells) were co-cultured with HTLV-1-infected T cell lines (Fig. 2i).

Transient contact with HTLV-1-infected cell lines leads to long-term cytopathic effects on astrocytoma cell lines

In the following set of experiments, we were interested to investigate the long term impact of HTLV-1 infected $\mathrm{T}$ cells on astrocytes cell lines, including the morphological and ultra structural alterations and induction of apoptosis. For this purpose, we co-cultured astrocytoma cells (U251 and U87) with infected (CIB) or non-infected $\mathrm{T}$ cell lines (CEM). After $3 \mathrm{~h}$ interaction, lymphocyte cell lines were removed from the co-cultures through vigorous cold PBS washings. Complete removal of T cell lines was confirmed in paired co-cultures stained by Giemsa and observed by light microscopy. The astrocytoma cells were then kept in culture for up to 10 days with daily microscopic observation. Figure 3 shows that 5 days after lymphocyte removal, the astrocytoma cells exhibited important changes characterized by cell shrinkage, loss of cell-cell contact, detachment from the monolayer and cell death (Fig. 3c, f).

These changes were further characterized by transmission electron microscopy (Fig. 3g-i). Astrocytoma cell lines in the monolayers that have been transiently exposed to HTLV-1 (but not to non-infected) T cell lines, exhibited ultrastructural alterations, characterized by severe cell shrinkage, loss of cell-cell contact (Fig. 3i) and accumulation of secondary lysosomes (Fig. 3j). These changes were evident as early as 3 days post washing of $\mathrm{T}$ cell lines. In addition, virus-like particles were observed within the cytoplasm of the astrocytoma cells, suggesting that they become infected by HTLV-1 (Fig. 3j, i).

No morphological changes were observed in the mock control (cultures of astrocytoma cells in absence of any T lymphocyte cell lines, Fig. 3a, d and g) and the monolayer previously co-cultured with the non-infected CEM T cell line (Fig. 3b, e, h), as ascertained by Giemsa staining and by electron microscopy. In order to control for nonspecific effects of HTLV-1-infected T cell lines on astrocytoma cell lines, similar experiments were performed using Hela cells, and no morphological alterations were detected in these cells upon interactions with HTLV-1infected cell lines (Fig. 4).

Subsequent experiments were performed in order to investigate if the cytopathic effect described above involved increased apoptosis. We thus performed annexin $\mathrm{V}$ plus propidium iodide staining (measured by cytofluorometry) in astrocytoma cell lines after short-term interaction with each $\mathrm{T}$ cell line. Figure 5 shows that transient contact with HTLV-1-infected T lymphocyte cell lines resulted in enhanced annexin $\mathrm{V}$ labeling (as compared to the values obtained with the non-infected $\mathrm{T}$ cell 


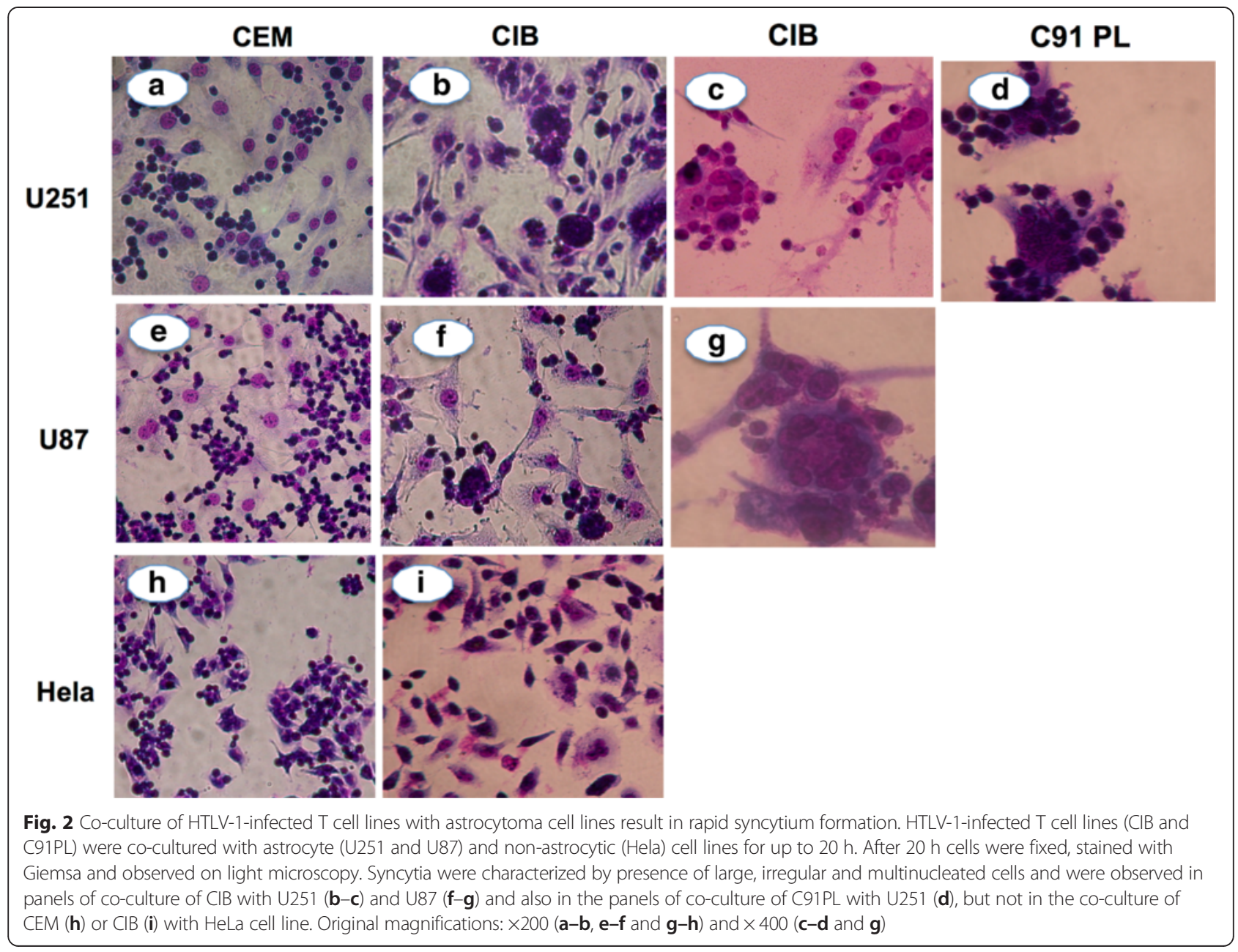

line), suggesting increased apoptosis, as further discriminated from necrotic cell death by the propidium iodide staining profiles.

Expression pattern of cell adhesion and migration-related genes in astrocytoma cell lines following short-term incubation with supernatants from $\mathrm{HTLV}-1^{+} \mathrm{T}$ cell lines

Since soluble factors secreted by HTLV-1 infected T cell lines, particularly soluble Tax 1 protein, have been described to exert paracrine effect on target cells [15], we investigated whether supernatants from $\mathrm{HTLV}-1^{+} \mathrm{T}$ cell lines could affect the expression of cell adhesion and migration-related genes on astrocytoma cell lines. Indeed, transient exposure (30 $\mathrm{min}$ ) to fractionated supernatants from the HTLV-1 ${ }^{+}$cell lines resulted in statistically significant increase in the mRNA expression of various cytokines/chemokines and adhesion molecules, including the pro-inflammatory cytokine TNF- $\alpha$, the TNF- $\alpha-$ regulated chemokines CXCL1, CXCL2, CXCL3, CXCL8, CCL2, IL13 and CXCL10, as well as V-CAM-1 and MMP8 , as compared to the values obtained when the astrocytoma cells were subjected to supernatants from non-infected T cell line cultures (Fig. 6).

Of note, although not statistically significant, qPCR values for gene expression for various other chemokines and ECM/adhesion molecules were slightly higher (Additional file 1: Figure S1A-D and Additional file 2: Figure S2A-D).

\section{Enhanced migration of HTLV-1-infected T cell lines after} stimulation with supernatants from primed astrocytoma cell lines

Considering that the expression pattern of various cell migration-related genes was up-regulated in the astrocytoma cell lines cultured in presence of supernatants from HTLV $-1^{+}$T cell lines, it was plausible to hypothesize that, once astrocytes are primed by a first wave of infiltrating $\mathrm{T}$ cells, they might play a role in the further recruitment of $\mathrm{T}$ cells into the central nervous system. In order to address this issue we applied supernatants from astrocytoma cell cultures (U251) previously primed with a transient exposure with the HTLV-1 infected (CIB) or non-infected (CEM) T cell lines, as migratory stimuli for the migration 


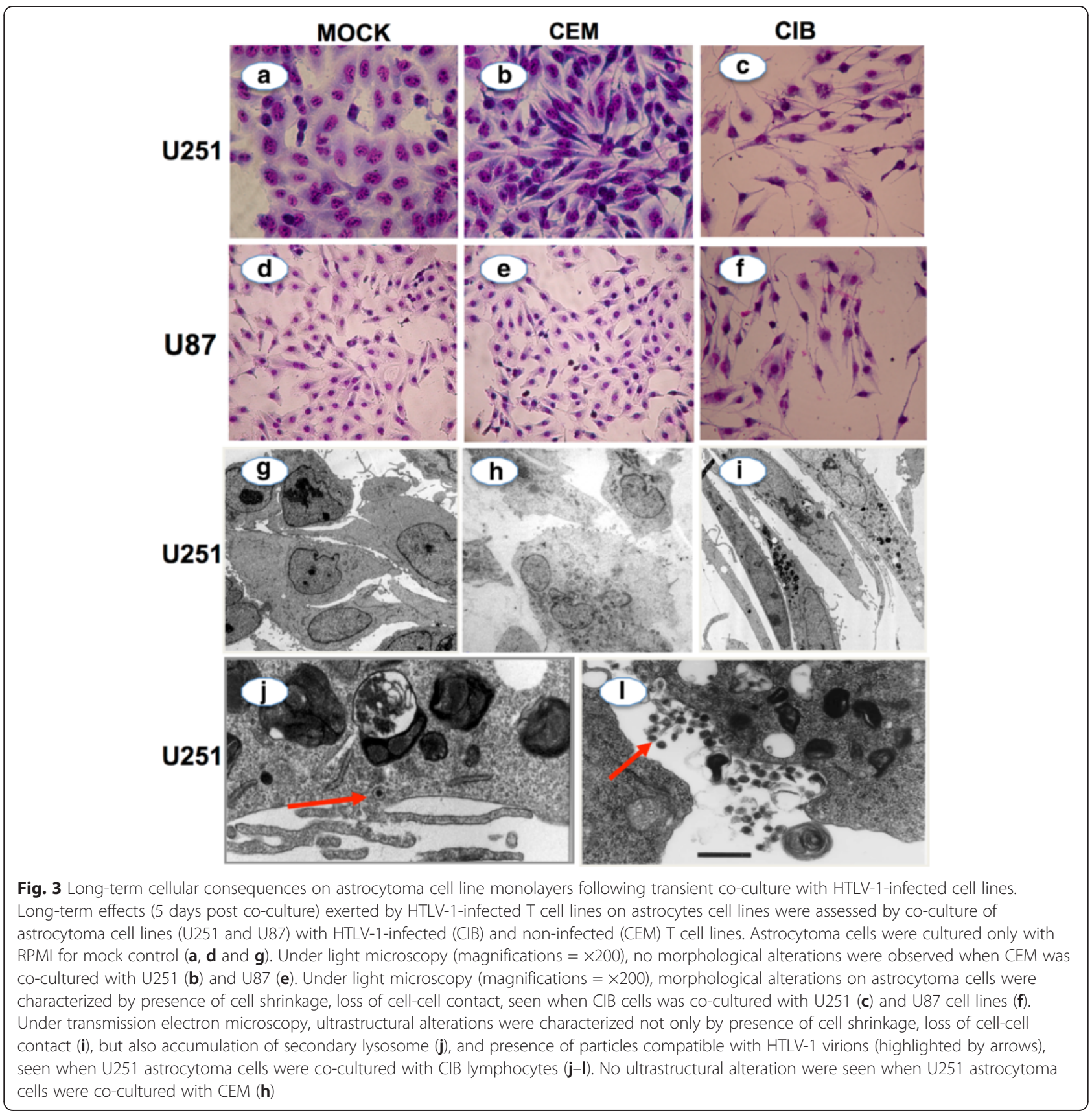

of further HTLV-1 ${ }^{+} \mathrm{T}$ cells. Migratory response of these cells to supernatant of astrocytoma cell lines primed with infected cell lines was significantly enhanced, as compared to supernatants from untreated astrocytoma cell lines, or those co-cultured with the non-infected T cell line (Fig. 7).

\section{Discussion}

The mechanisms underlying the pathogenesis of HAM/ TSP are still poorly understood. Although previous evidence strongly suggests that astrocytes take part in this process through several mechanisms [30-32], their participation in the migration of $\mathrm{T}$ cells into the $\mathrm{CNS}$ has not been studied in deep. Given the central role of astrocytes in the functional and structural homeostasis of the CNS [28], any impairment of these cells would potentially compromise CNS functional and structural integrity. A better understanding of these processes is thus essential for designing future effective therapeutic and preventive strategies. In this context, we investigated the effects exerted by HTLV-1 on astrocytes using an in vitro model of heterocellular interaction involving $\mathrm{T}$ cell lines and astrocytoma cell. Experimentally, we used a $\mathrm{T}$ cell line derived from a HAM/TSP patient (CIB), a $\mathrm{T}$ cell line originally infected by HTLV- 

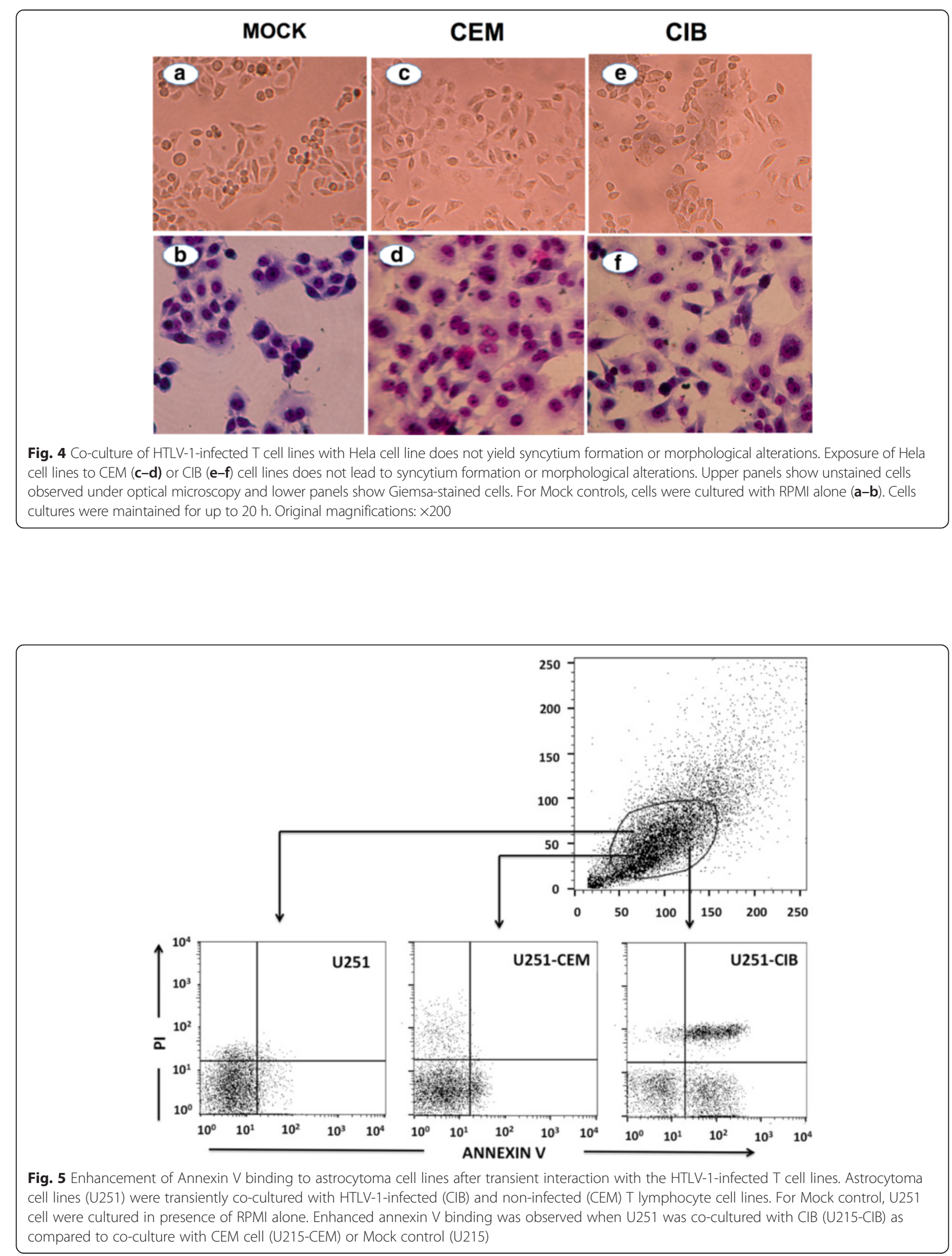

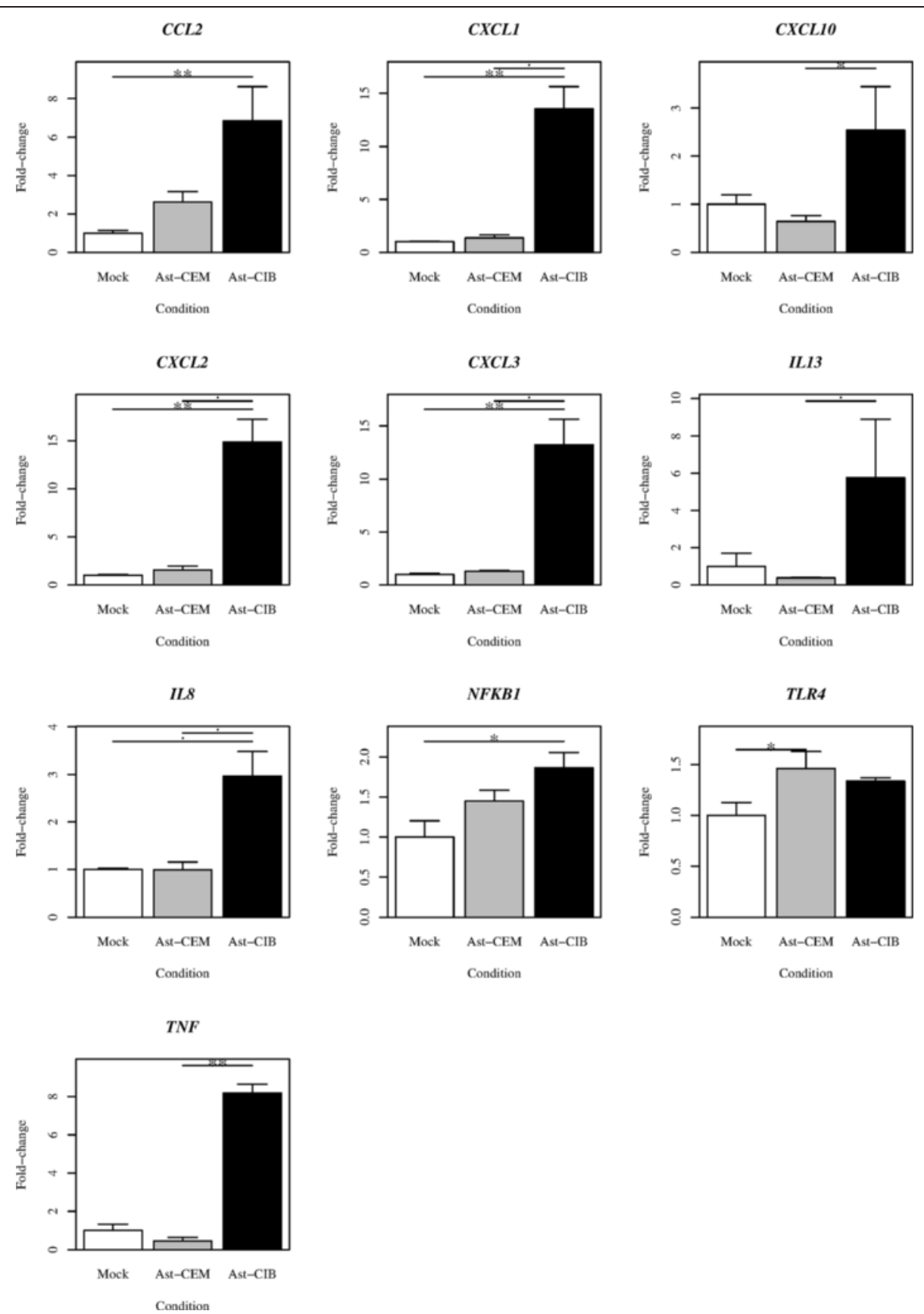

Fig. 6 Modulation of cell adhesion and migration-related gene expression in astrocytoma cell lines after transient exposure to supernatants of HTLV-1-infected T cell lines. Astrocytoma cell lines (U251) were primed with supernatants from CIB (Ast-CIB) and CEM (Ast-CEM) T cells cultures. For Mock control, astrocytoma cells were treated with RPMl alone (Mock). After $1 \mathrm{~h}$ of exposure, cells were washed, harvested and RNA was extracted. Ast-CIB expressed statistically significant higher amounts of RNA for all illustrated genes as compared to Ast-CEM and Mock. Data derive from 3 independent experiments

1 in vitro (C91PL) and two astrocytoma cell lines (U251 and U87).

We first demonstrated that HTLV-1-infected T cell lines adhered significantly higher to the astrocytoma monolayers as compared to the non-infected $\mathrm{T}$ cell line. This finding suggests that astrocytes may represent a critical target of HTLV-1 infected lymphocytes. Previous studies also demonstrated that HTLV-1 infected cell lines adhered stronger to endothelial cell lines [35]. We also observed that co-culture of astrocytoma cell lines with HTLV-1 infected, (but not with non-infected) T cell lines, resulted in rapid syncytium formation, seen as 


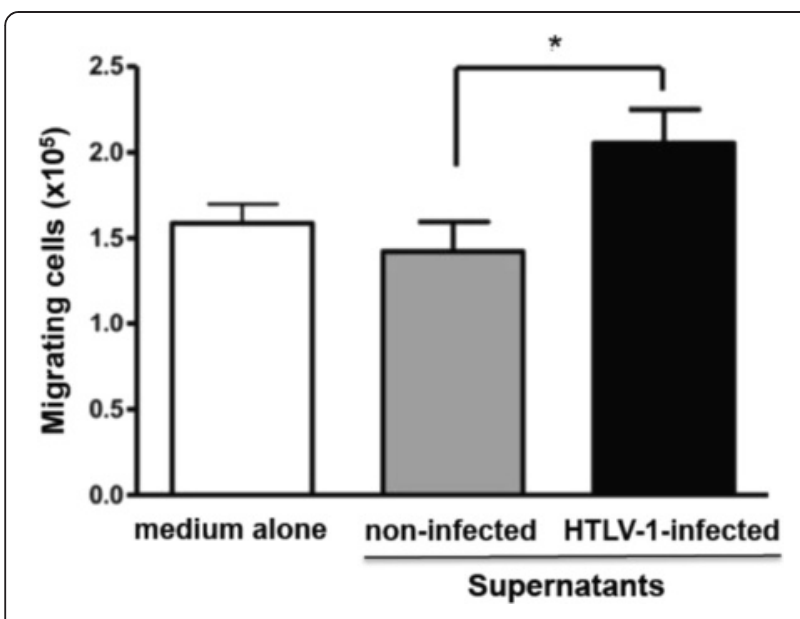

Fig. 7 Enhanced migratory response of HTLV-1-infected T lymphocyte cell lines treated with supernatants from astrocytoma cell lines primed after transient interaction with HTLV-1-infected T cell lines. The HTLV-1infected T cell line (CIB) was allowed to migrate in transwell chambers whose bottom wells contained supernatants from astrocytoma cell cultures that were primed with HTLV-1-infected versus non-infected T cell lines. Migrating cells, harvested in the lower chambers, were counted using trypan blue cell viability analysis. Values correspond to mean \pm standard error of 3 independent experiments for each $T$ cell line. ${ }^{*} p<0.05$

early as $6 \mathrm{~h}$ post co-culture. In addition, no syncytium was observed when a non-astrocyte cell line was used as a control, demonstrating that this effect is at least to some extent cell type specific. This result is in agreement with previous observations, in which rapid syncytium formation was detected when HTLV-1 infected lymphocyte cell lines were co-cultured with astrocyte cell lines [32]. These findings allow us to hypothesize that HTLV-1 infected cells have an increased ability to cross the blood-brain barrier into the CNS, where they rapidly and strongly bind to the astrocytoma, leading to severe functional and morphological damage.

In a second set of experiments, we observed several and extensive morphological changes and cytopathic effect in 5day culture of astrocytoma cell cultures that were transiently exposed to HTLV-1-infected T cell lines, but not to non-infected counterparts. The cytopathic effect was characterized by loss of cell-cell contact, cell shrinkage, accumulation of lysosomal vesicles and cell death. Notably, similar morphological alterations have been observed in endothelial cells after transient interaction with the MT-2 HTLV-1 ${ }^{+}$ $\mathrm{T}$ cell line [35]. These alterations were rather cell type specific since co-culture of HTLV-1 infected T cell lines with the Hela cell line, a non-astrocytic lineage, did not result in any cytopathic effect (see Fig. 4). We also detected an enhancement of astrocytoma apoptosis secondary to the interaction with HTLV-1-infected cells as shown in Fig. 5, a finding corroborated by similar results previously reported [36-38]. Several mechanisms has been proposed to explain the apoptotic effect of HTLV-1 infected T cells on astrocytes, such as the direct effect of secreted Tax-1 protein in inducing apoptotic pathways in the target cell through the down regulation in the cellular expression of $b c l-2[36,37]$ and susceptibility of astrocytes to apoptosis secondary to increase in the production of TNF- $\alpha$ [38].

Of note, we observed the presence of HTLV-1 viral particles in the cytoplasm of astrocytoma cells after transient interaction with HTLV-1 ${ }^{+}$T cells line, but not with the non-infected $\mathrm{T}$ cell line. Infection of astrocytes with HTLV-1 has been reported in previous studies [39-41], and suggests that direct infection may also be involved in the functional and morphological damage of human astrocytes in HAM/TSP.

We also investigated the role played by the soluble factors secreted by $\mathrm{HTLV}-1^{+} \mathrm{T}$ cell lines on cultured astrocyte cell lines. We used qPCR arrays to quantitatively evaluate the expression levels of a large numbers of cell migration-related genes, including cytokines/chemokines and extracellular matrix/cell adhesion proteins. A short-term $(1 \mathrm{~h})$ exposure of astrocytoma cell lines to fractionated HTLV-1-infected T cell lines-derived supernatants, resulted in statistically significant increase in the mRNA of TNF- $\alpha$, various chemokines, as well as VCAM-1 and MMP-8, as compared with supernatants derived from the non-infected $\mathrm{T}$ cell line, as shown in Fig. 6 . These results strongly corroborate the findings reported by Ando and cols. (2013), who found an increased CXCL10 production by astrocytes that were transiently co-cultured with CIB cells [42] and also with results reported by Tomoo and cols. (2013), who found that level of CXCL10 in the CSF correlated with progression to HAM/TSP [43], suggesting that CXCL10 might play a critical role in stimulating migration of HTLV-1 infected $\mathrm{T}$ cells in the transwell chamber and ultimately reflecting what happens in vivo, when T-cells migrate into the CNS. Our results are also in line with previous histopathological findings from post-mortem tissues, in which it has been found that astrocytes from HAM/TSP lesions exhibit higher contents of proinflammatory cytokines, MMP and chemokines [14, 29, 30].

Moreover, our data corroborate those described by Akaoka (2011) and Szymocha (2000), who demonstrated that infiltrating HTLV-1-infected T lymphocytes in the CNS continuously induce significant changes in astrocytes, not only through cell-cell interaction [44], but also through soluble elements, particularly the $42 \mathrm{kDa}$ Tax-1 viral protein [31]. Tax is a transactivator/oncoprotein thought to play an important role in the course of HAM/TSP, and soluble Tax1 has been shown to induce functional changes in human astrocytes [36] and to modulate gene expression on target cells [15].

Conjointly, these findings strongly point to an important paracrine effect of HTLV-1 infected lymphocytes on 
astrocytes and highlight that the functional impairment of astrocytes occurring in HAM/TSP, would be much more complex than ever described.

Our findings suggest that the functional impairment of astrocytes caused by interactions with HTLV-1-infected $\mathrm{T}$ cells contributes to the perpetuation and amplification of the CNS damage. Considering that we applied a 30$50 \mathrm{kDa}$ supernatant fraction to stimulate the astrocytoma cells, it is conceivable that Tax1 protein is involved in these effects. Yet, additional studies with blocking antibodies are required to confirm this hypothesis.

Since astrocytes primed with HTVL-1-infectd T cells expressed higher levels of various cell adhesion and migration-related mRNA molecules, it seemed plausible to hypothesize that supernatants from such primary cultures could enhance T cell migration. Actually, this was the case and supernatants from HTLV-1 primed astrocytoma cell lines were able increase the migration of HTLV-1 infected T cell lines. Conceptually, these data suggest that activated astrocytes would enhance the recruitment of additional T cells into the CNS. Since main focus of this study was to understand the impact of a HAM/TSP derived $T$ cell line (CIB), the in vitro derived HTLV-1 infected $\mathrm{T}$ cell line (C91PL) was used as a control only in the first set of experiments when we observed that the effects were similar when using both cell lines.

Although we have not performed immune staining to confirm the presence of HTLV-1 inside the cells, we believe that the viral particle detection by electron microscopy is a convincing evidence of astrocyte infection. Similarly, we also think that the enhanced T cell migration after being primed by supernatants from infected astrocytes suggests an increased concentration of chemotactic factors, as indicated by the elevated expression of the corresponding mRNAs by HTLV-1-infected astrocytes.

Of remark, our results are of utmost importance, since most of the previous work that investigated HTLV-1-induced changes on astrocytes used in vitro derived HTLV-1-infected T cell lines, such as MT-2 or C91PL [29, 31-34, 45]. In our study we used a HAM/TSP patient-derived lymphocyte T cell line. Indeed, to our knowledge, only Ando and co-workers conducted functional assays on astrocytes using same cell line [42].

\section{Conclusion}

In conclusion, our results show that HAM/TSP-derived $\mathrm{T}$ lymphocyte cell lines exert a pleiotropic effects upon astrocyte cell lines, leading to astrocyte damage and increased secretion of attracting cytokines, which in turn may participate in the further attraction of HTLV-1-infected T cells into central nervous system (CNS), thus amplifying and prolonging the immune damage of CNS.

\section{Methods \\ Cell lines}

The human malignant astrocytoma cell lines U251 and U87, both derived from malignant gliobastoma multiforme (gently provided by Dr Maria do Socorro Pombo de Oliveira, National Cancer Institute, Rio de Janeiro) [46], were grown in high glucose (4500 mg/l) Dulbecco Modified Eagle Medium (DMEM; Gibco-BRL, Grand Island, NY) supplemented with $10 \%$ fetal calf serum (FCS) (Cultilab, Campinas, Brasil), $2 \mathrm{mM}$ L-glutamine (Gibco, Scotland, UK), $100 \mathrm{U} / \mathrm{ml}$ penicillin and $100 \mathrm{~g} /$ $\mathrm{ml}$ streptomycin (Gibco, Scotland, UK) at $37{ }^{\circ} \mathrm{C}$ in a humidified incubator with $5 \% \mathrm{CO}_{2}$. Hela cells, an epithelial cell line derived from cervical cancer cells [47], were used as a negative control in some experiments. The HTLV-1-infected T cell line CIB (gently provided by Dr. Olivier Hermine, Necker Hospital, Paris) was derived from a HAM/TSP patient [48]. The HTLV-1-infected T cell line C91PL was derived from human cord blood $\mathrm{T}$ lymphocytes immortalized by HTLV-I infection [49] (used in several assays as a positive control and gently provided by Dr. Olivier Hermine, Necker Hospital, Paris). The non-infected T-cell line CEM, derived from a patient with acute lymphoblastic leukemia, [50] (used as a negative control and gently provided by Dr Maria do Socorro Pombo de Oliveira, National Cancer Institute, Rio de Janeiro) was cultured in RPMI 1640 supplemented with $10 \%$ fetal calf serum, $100 \mathrm{U} / \mathrm{ml}$ penicillin and $100 \mathrm{~g} / \mathrm{ml}$ streptomycin at $37{ }^{\circ} \mathrm{C}, 5 \% \mathrm{CO}_{2}$. Cultures of the HTLV-1-infected T cell lines were further supplemented with $100 \mathrm{U} / \mathrm{ml}$ of interleukin 2 (IL-2) (Roche, France).

\section{Heterocellular adhesion assay}

For adhesion assays, astrocytoma and Hela cells were first plated in $25 \mathrm{~cm}^{2}$ flasks until sub-confluence. Then, HTLV-1-infected or non-infected T lymphocytes were added to the astrocyte monolayer at a ratio astrocyte: lymphocyte of $1: 4$ and allowed to adhere for $30 \mathrm{~min}$ at $37{ }^{\circ} \mathrm{C}, 5 \% \mathrm{CO}_{2}$ in RPMI 1640 supplemented with $2 \mathrm{mM}$ L-glutamine and antibiotics in absence of FCS and IL-2. Supernatants containing floating lymphocytes were then discarded and the contents of each flask (astrocytes + adhered lymphocytes) were fixed in absolute ethanol, stained with Giemsa and counted to determine the adhesion index (AI), as previously described [51] and validated for this type of analysis [52], using the following formula: 


$$
\begin{aligned}
\mathrm{AI}= & \frac{\text { Astrocytes with adhered lymphocytes }}{\text { Total number of astrocytes }} \\
& \times \frac{\text { Lymphocytes adhered to astrocytes }}{\text { Total number of astrocytes }} \times 100
\end{aligned}
$$

\section{Assessment of syncytium formation}

To assess syncytium formation, astrocytoma cells were initially grown in $25 \mathrm{~cm}^{2}$ flasks until sub-confluence. HTLV-1-infected T lymphocytes (CIB or C91PL) or the non-infected $\mathrm{T}$ cell line (CEM) were added to the monolayer of astrocytoma at astrocyte/lymphocyte ratio of 1:4 and left to adhere for up to $20 \mathrm{~h}$ in culture conditions similar to those described above. Supernatant was then discarded, washed briefly with PBS, fixed in absolute ethanol, stained with Giemsa and observed by light microscopy. Similar assays were performed using a nonastrocytic cell line (Hela), to assess whether changes were specific for astrocytes.

\section{Morphological assessment of cultured astrocytoma cells}

Astrocytoma cells were initially grown in $25 \mathrm{~cm}^{2}$ flasks until sub-confluence. Transient co-cultures of astrocytes with either HTLV-1-infected T lymphocytes (CIB or C91PL) or the non-infected $\mathrm{T}$ cell line (CEM) were performed by replacing the medium in the astrocytoma cultures with those from cultures of HTLV-1-infected or non-infected T cell lines in the absence of IL-2 at $37{ }^{\circ} \mathrm{C}$, $5 \% \mathrm{CO}_{2}$, at astrocyte/lymphocyte ratio of 1:4. After $3 \mathrm{~h}$, lymphocytes were completely removed from the cultures by vigorous washing using cold PBS. Duration of coculture was set at $3 \mathrm{~h}$, since the study conducted by Mor-Vaknin et al., [32], demonstrated that syncytium was formed as early as $4 \mathrm{~h}$ post co-culture and in our experiments syncytium was formed as early as $6 \mathrm{~h}$ post co-culture.

Hela cells were used as controls for nonspecific interactions between astrocytes and HTLV-1-infected cells. For Mock controls, astrocytes were culture alone with RPMI.

After lymphocyte removal by vigorous washings with cold PBS, astrocytoma and Hela cells were kept in culture for up to 5 days, replenishing fresh medium every two days. At days 5 post co-culture, astrocytes were processed for optical or transmission electron microscopy, as previously described [53], using current $2.5 \%$ glutaraldehyde $1 \%$ paraformaldehyde fixation, followed by uranyl acetate plus lead citrate staining, with the analysis of ultrathin sections being done under a transmission electron microscope (Jeol JEM-1011) on the Rudolf Barth Electron Microscopy Platform at the Oswaldo Cruz Institute (Fiocruz, Rio de Janeiro).

\section{Apoptosis of astrocytoma cells induced by HTLV-1- infected lymphocytes}

The ability of HTLV-1 or non-infected T cells to induce apoptosis on the astrocytoma cells was measured by cytofluorometry using FITC-coupled Annexin V Apoptosis Detection Kit I (Becton-Dickinson/Pharmingen, San Diego). After transient co-cultures during $3 \mathrm{~h}$, followed by lymphocyte removal by vigorous washings with cold PBS, astrocytes were kept in culture for additional $2 \mathrm{~h}$, trypsinized and stained with FITC-Annexin V and Propidium Iodide according to the manufacturer's instructions. Events were acquired using a FACSCalibur Flow Cytometer (BectonDickinson, San Diego, USA).

\section{Cell adhesion and cell migration-related gene expression of astrocytoma cells primed with supernatants from HTLV-1-infected T lymphocytes}

We further evaluated the effect exerted by HTLV-1infected cells on the expression of cell adhesion and cell migration-related genes in astrocytoma cells. Astrocytes were primed using supernatants from HTLV-1-infected $\mathrm{T}$ cell cultures, using as control counterpart supernatants from non-infected T cell cultures. For this purpose, lymphocytes were grown in $75 \mathrm{~cm}^{2}$ culture flasks at an initial concentration of $1 \times 10^{7}$ cells/mL during $24 \mathrm{hs}$. Supernatants were then collected and concentrated using the centripep YM-50 and YM-30 filters (Millipore, corporation, County Cork, Ireland), according to the manufacturer's instructions. The fraction was added to the astrocyte monolayer for $1 \mathrm{~h}$ at $37^{\circ} \mathrm{C}$ and then, cells were then trypsinized and washed. As a mock control, growing astrocytes were treated with RPMI alone.

Total RNA was extracted using RNeasy Micro Kit (Qiagen, Hilden, Germany), according to the manufacturers instructions, including DNAse treatment. Total RNA was quantified by spectrophotometry using Nanodrop 2000 (Thermo Scientific, USA). RNA integrity was assessed for the presence of ribosomal RNA $28 \mathrm{~S}$ and $18 \mathrm{~S}$, using denaturating agarose gel electrophoresis as previously described [54]. RNA was used for the RTPCR if the ratio $A_{260} / A_{230} \approx 2.0$.

Gene expressing profiles for cytokines/chemokines and extracellular matrix (ECM) proteins/adhesion molecules were ascertained by quantitative PCR. cDNAs were prepared from $1 \mu \mathrm{g}$ RNA of each sample using "RT" First Strand" (SABioscience, Maryland, USA), according to the manufacturers instructions. Then, $\mathrm{RT}^{2}$ SYBR Green/ROX PCR Master Mix (SABioscience) and' nuclease-free water were added to the cDNA. Twentyfive $\mu \mathrm{L}$ of this mixture were added to 96 microplates containing primers for each of the 84 target genes for ECM proteins/adhesion molecules using corresponding qPCR arrays (SABioscience/Qiagen, USA), as seen in supplementary data in S1 Table and S2 Table. Amplification 
signals were captured using the ABI Prism 7000 PCR device (Applied Biosystems, Foster City, CA, USA). Melting curve analysis was performed for each sample at the end of the PCR.

\section{Migration profile of HTLV-1-T lymphocytes cell lines under the stimulation of supernatants from primed astro- cytoma cell lines}

Cell migration studies were conducted in transwell chambers (Corning Costar, Cambridge, MA, USA), as described elsewhere [55], using the $8-\mu \mathrm{m}$ pore size inserts coated with $10 \mu \mathrm{g} / \mathrm{ml}$ of BSA, for $1 \mathrm{~h}$ at $37^{\circ} \mathrm{C}$. Supernatants from astrocytoma cultures previously primed with HTLV-1-T cell lines (3 h co-culture) were harvested and added into the lower chamber, whereas $10^{6} \mathrm{CIB}$ cells $/ 100 \mu \mathrm{l}$ (of RPMI/1 \% BSA) were added into the upper chambers. After $4 \mathrm{~h}$ incubation at $37^{\circ} \mathrm{C}$ in $5 \% \mathrm{CO}_{2}$, we counted the cells that migrated into the lower chambers using trypan blue cell viability analysis.

\section{Statistical analysis}

All statistical analyses were performed using the GraphPad Prism 5.01 software package. Quantitative data were expressed as the mean \pm standard error. The Student's $t$ test and the One Way ANOVA test were used to compare the differences among groups. Differences were considered statistically significant when the p values were $\leq 0.05$.

\section{Additional files}

Additional file 1: Figure S1. Cytokine/Chemokine gene expression in astrocytoma cell line after transient exposure to supernatants of HTLV-1infected T cell lines. The astrocyte cell line (U251) was primed with supernatants from cultured CIB (Ast-CIB) and CEM (Ast-CEM) T cells. For Mock control, astrocytoma cells were treated with RPMI alone (Mock). After $1 \mathrm{~h}$ of exposure, cells were washed, harvested and RNA was extracted. Ast-CIB expressed statistically significant higher amounts of RNA for all illustrated genes as compared to Ast-CEM and Mock. Data derive from 3 independent experiments. (PDF $614 \mathrm{~kb}$ )

Additional file 2: Figure S2. Extracellular matrix proteins gene expression in astrocytoma cell lines after transient exposure to supernatants of HTLV-1-infected T cell lines. The astrocytoma (U251) were primed with supernatants from cultured CIB (Ast-CIB) and CEM (Ast-CEM) $T$ cell lines. For Mock control, astrocytoma cells were treated with RPMI alone (Mock). After $1 \mathrm{~h}$ of exposure, cells were washed, harvested and RNA was extracted. Ast-CIB expressed statistically significant higher amounts of RNA for all illustrated genes as compared to Ast-CEM and Mock. Data derive from 3 independent experiments. (PDF 592 kb)

\section{Competing interests}

The authors declare that they have no competing interests.

\section{Authors' contributions}

ESG designed the study, collected and analyzed data and wrote the manuscript; LLL designed the study, performed experiments and wrote the manuscript; MRA designed and analyzed QPCR assays; SCR processed samples for and analyzed electron microscopy data; DCBH designed experiments, analyzed data and wrote the manuscript; SDSB and WS designed study, analyzed data and wrote the manuscript. Authors declare no financial or personal interest. All authors have read and approved the final version of the manuscript.

\section{Acknowledgments}

We would like to thank the entire team of the Laboratory on Thymus Research for their support during this study.

\section{Author details}

${ }^{1}$ National Institute of Health, Ministry of Health, Av. Eduardo Mondlane, 1008 Maputo, Mozambique. ${ }^{2}$ Laboratory on Thymus Research, Oswaldo Cruz Institute, Oswaldo Cruz Foundation, Rio de Janeiro, Brazil. ${ }^{3}$ National Cancer Institute, Rio de Janeiro, Brazil. ${ }^{4}$ Laboratory of Structural Biology, Oswaldo Cruz Institute, Oswaldo Cruz Foundation, Rio de Janeiro, Brazil.

Received: 30 June 2015 Accepted: 1 October 2015

Published online: 12 October 2015

\section{References}

1. Osame M. Pathological mechanisms of human T-cell lymphotropic virus type I-associated myelopathy (HAM/TSP). J Neurovirol. 2002;8:359-64.

2. Gessain A, Barin F, Vernant JC, Gout O, Maurs L, Calender A, et al. Antibodies to human T-lymphotropic virus type-l in patients with tropical spastic paraparesis. Lancet. 1985;2:407-10

3. Takatsuki K. Discovery of adult T-cell leukemia. Retrovirology. 2005;2:16.

4. Edlich RF, Hill LG, Williams FM. Global epidemic of human T-cell lymphotrophic virus type-I (HTLV-I): an update. J Long Term Eff Med Implants. 2003;13:127-40.

5. Proietti FA, Carneiro-Proietti AB, Catalan-Soares BC, Murphy EL. Global epidemiology of HTLV-I infection and associated diseases. Oncogene. 2005:24:6058-68.

6. Verdonck K, Gonzalez E, Van Dooren S, Vandamme AM, Vanham G, Gotuzzo E. Human T-lymphotropic virus 1: recent knowledge about an ancient infection. Lancet Infect Dis. 2007;7:266-81.

7. Touze E, Gessain A, Lyon-Caen O, Gout O. Tropical spastic paraparesis/HTLV-Iassociated myelopathy in Europe and in Africa: clinical and epidemiologic aspects. J Acquir Immune Defic Syndr Hum Retrovirol. 1996;13 Suppl 1:S38-45.

8. Mueller N. The epidemiology of HTLV-I infection. Cancer Causes Control. 1991;2:37-52.

9. Nagai M, Osame M. Human T-cell lymphotropic virus type I and neurological diseases. J Neurovirol. 2003;9:228-35.

10. Iwasaki Y. Human T, cell leukemia virus type I infection and chronic myelopathy. Brain Pathol. 1993;3:1-10.

11. Rodgers-Johnson PE. Tropical spastic paraparesis/HTLV-I associated myelopathy. Etiology and clinical spectrum. Mol Neurobiol. 1994;8:175-9.

12. Hollsberg P. Pathogenesis of chronic progressive myelopathy associated with human T-cell lymphotropic virus type I. Acta Neurol Scand Suppl. 1997;169:86-93.

13. Biddison WE, Kubota R, Kawanishi T, Taub DD, Cruikshank WW, Center DM, et al. Human T cell leukemia virus type I (HTLV-I)-specific CD8+ CTL clones from patients with HTLV-I-associated neurologic disease secrete proinflammatory cytokines, chemokines, and matrix metalloproteinase. J Immunol. 1997;159:2018-25.

14. Umehara F, Izumo S, Ronquillo AT, Matsumuro K, Sato E, Osame M. Cytokine expression in the spinal cord lesions in HTLV-I-associated myelopathy. J Neuropathol Exp Neurol. 1994:53:72-7.

15. Cowan EP, Alexander RK, Daniel S, Kashanchi F, Brady JN. Induction of tumor necrosis factor alpha in human neuronal cells by extracellular human T-cell lymphotropic virus type 1 Tax. J Virol. 1997;71:6982-9.

16. Moore GR, Traugott U, Scheinberg LC, Raine CS. Tropical spastic paraparesis: a model of virus-induced, cytotoxic T-cell-mediated demyelination? Ann Neurol. 1989;26:523-30.

17. Izumo S, Umehara F, Kashio N, Kubota R, Sato E, Osame M. Neuropathology of HTLV-1-associated myelopathy (HAM/TSP). Leukemia. 1997;11 Suppl 3:82-4.

18. Matsuoka E, Takenouchi N, Hashimoto K, Kashio N, Moritoyo T, Higuchi I, et al. Perivascular T cells are infected with HTLV-I in the spinal cord lesions with HTLV-I-associated myelopathy/tropical spastic paraparesis: double staining of immunohistochemistry and polymerase chain reaction in situ hybridization. Acta Neuropathol. 1998:96:340-6.

19. Iwasaki Y, Sawada K, Aiba I, Mukai E, Yoshida M, Hashizume Y, et al. Widespread active inflammatory lesions in a case of HTLV-I-associated myelopathy lasting 29 years. Acta Neuropathol. 2004;108:546-51. 
20. Aye MM, Matsuoka E, Moritoyo T, Umehara F, Suehara M, Hokezu Y, et al. Histopathological analysis of four autopsy cases of HTLV-I-associated myelopathy/tropical spastic paraparesis: inflammatory changes occur simultaneously in the entire central nervous system. Acta Neuropathol. 2000;100:245-52.

21. Nakamura T. HTLV-l-associated myelopathy/tropical spastic paraparesis (HAM/TSP): the role of HTLV-l-infected Th1 cells in the pathogenesis, and therapeutic strategy. Folia Neuropathol. 2009;47:182-94.

22. Izumo S, Umehara F, Osame M. HTLV-I-associated myelopathy. Neuropathology. 2000;20(Suppl):S65-8.

23. Nagai M, Yamano Y, Brennan MB, Mora CA, Jacobson S. Increased HTLV-I proviral load and preferential expansion of HTLV-I Tax-specific CD8+ T cells in cerebrospinal fluid from patients with HAM/TSP. Ann Neurol. 2001;50:807-12.

24. Iwasaki Y, Ohara Y, Kobayashi I, Akizuki S. Infiltration of helper/inducer T lymphocytes heralds central nervous system damage in human T-cell leukemia virus infection. Am J Pathol. 1992;140:1003-8.

25. Giraudon P, Malcus C, Chalon A, Vincent P, Khuth S, Bernard A, et al. Astrocytes, cells involved in neuro-immune interactions in the central nervous system. J Soc Biol. 2003;197:103-12.

26. Koehler RC, Gebremedhin D, Harder DR. Role of astrocytes in cerebrovascular regulation. J Appl Physiol. 2006;100:307-17.

27. Markiewicz I, Lukomska B. The role of astrocytes in the physiology and pathology of the central nervous system. Acta Neurobiol Exp (Wars). 2006:66:343-58.

28. Sofroniew MV, Vinters HV. Astrocytes: biology and pathology. Acta Neuropathol. 2010;119:7-35.

29. Giraudon P, Szymocha R, Buart S, Bernard A, Cartier L, Belin MF, et al. T lymphocytes activated by persistent viral infection differentially modify the expression of metalloproteinases and their endogenous inhibitors, TIMPs, in human astrocytes: relevance to HTLV-I-induced neurological disease. J Immunol. 2000;164:2718-27.

30. Giraudon P, Buart S, Bernard A, Belin MF. Cytokines secreted by glial cells infected with HTLV-I modulate the expression of matrix metalloproteinases (MMPs) and their natural inhibitor (TIMPS): possible involvement in neurodegenerative processes. Mol Psychiatry. 1997;2:107-10. 184.

31. Szymocha R, Akaoka H, Brisson C, Beurton-Marduel P, Chalon A, Bernard A, et al. Astrocytic alterations induced by HTLV type 1-infected T lymphocytes: a role for Tax-1 and tumor necrosis factor alpha. AIDS Res Hum Retroviruses. 2000;16:1723-9.

32. Mor-Vaknin N, Turgeman H, Torgeman A, Wolfson M, Huleihel M, Aboud M. Rapid syncytium formation between human T-cell leukaemia virus type-l (HTLV-I)-infected T-cells and human nervous system cells: a possible implication for tropical spastic paraparesis/HTLV-I associated myelopathy. Cell Biol Int. 1998;22:95-103.

33. Szymocha R, Akaoka H, Dutuit M, Malcus C, Didier-Bazes M, Belin MF, et al. Human T-cell lymphotropic virus type 1-infected T lymphocytes impair catabolism and uptake of glutamate by astrocytes via Tax-1 and tumor necrosis factor alpha. J Virol. 2000;74:6433-41.

34. Akaoka H, Hardin-Pouzet H, Bernard A, Verrier B, Belin MF, Giraudon P. Imbalanced expression of glutamate-glutamine cycle enzymes induced by human T-cell lymphotropic virus type 1 Tax protein in cultivated astrocytes. J Virol. 1996:70:8727-36.

35. Romero IA, Prevost MC, Perret E, Adamson P, Greenwood J, Couraud PO, et al. Interactions between brain endothelial cells and human T-cell leukemia virus type 1-infected lymphocytes: mechanisms of viral entry into the central nervous system. J Virol. 2000;74:6021-30.

36. Banerjee P, Rochford R, Antel J, Canute G, Wrzesinski S, Sieburg M, et al. Proinflammatory cytokine gene induction by human T-cell leukemia virus type 1 (HTLV-1) and HTLV-2 Tax in primary human glial cells. J Virol. 2007:81:1690-700

37. Jiang $X$. In vitro analysis of cell death of spinal oligodendrocytes in a rat model of HTLV-I infection. Hokkaido Igaku Zasshi. 2000;75:335-46.

38. Tomaru U, Ikeda H, Jiang X, Ohya O, Yoshiki T. Provirus expansion and deregulation of apoptosis-related genes in the spinal cord of a rat model for human T-lymphocyte virus type l-associated myeloneuropathy. J Neurovirol. 2003;9:530-8.

39. Lehky TJ, Fox CH, Koenig S, Levin MC, Flerlage N, Izumo S, et al. Detection of human T-lymphotropic virus type I (HTLV-I) tax RNA in the central nervous system of HTLV-l-associated myelopathy/tropical spastic paraparesis patients by in situ hybridization. Ann Neurol. 1995;37:167-75.
40. Macchi B, Caronti B, Cocchia D, Gremo F, Torelli S, Sogos V, et al. Correlation between P19 presence and MHC class II expression in human fetal astroglial cells cocultured with HTLV-I donor cells. Int J Dev Neurosci. 1992;10:231-41.

41. Nishiura Y, Nakamura T, Takino H, Ichinose K, Nagasato K, Ohishi K, et al. Production of granulocyte-macrophage colony stimulating factor by human T-lymphotropic virus type l-infected human glioma cells. J Neurol Sci. 1994;121:208-14

42. Ando H, Sato T, Tomaru U, Yoshida M, Utsunomiya A, Yamauchi J, et al. Positive feedback loop via astrocytes causes chronic inflammation in virusassociated myelopathy. Brain. 2013;136:2876-87.

43. Sato T, Coler-Reilly A, Utsunomiya A, Araya N, Yagishita N, Ando H, et al. CSF CXCL10, CXCL9, and neopterin as candidate prognostic biomarkers for HTLV-1-associated myelopathy/tropical spastic paraparesis. PLoS Negl Trop Dis. 2013;7:e2479.

44. Akaoka H, Szymocha R, Beurton-Marduel P, Bernard A, Belin MF, Giraudon P. Functional changes in astrocytes by human T-lymphotropic virus type-1 Tlymphocytes. Virus Res. 2001;78:57-66.

45. Watabe K, Saida T, Kim SU. Human and simian glial cells infected by human T-lymphotropic virus type I in culture. J Neuropathol Exp Neurol. 1989:48:610-9.

46. Ponten J, Macintyre EH. Long term culture of normal and neoplastic human glia. Acta Pathol Microbiol Scand. 1968;74:465-86.

47. Scherer WF, Syverton JT, Gey GO. Studies on the propagation in vitro of poliomyelitis viruses. IV. Viral multiplication in a stable strain of human malignant epithelial cells (strain HeLa) derived from an epidermoid carcinoma of the cervix. J Exp Med. 1953;97:695-710.

48. Blot V, Delamarre L, Perugi F, Pham D, Benichou S, Benarous R, et al. Human Dlg protein binds to the envelope glycoproteins of human T-cell leukemia virus type 1 and regulates envelope mediated cell-cell fusion in T lymphocytes. J Cell Sci. 2004;117:3983-93.

49. Markham PD, Salahuddin SZ, Kalyanaraman VS, Popovic M, Sarin P, Gallo RC. Infection and transformation of fresh human umbilical cord blood cells by multiple sources of human T-cell leukemia-lymphoma virus (HTLV). Int J Cancer. 1983;31:413-20.

50. Popovic M, Sarngadharan MG, Read E, Gallo RC. Detection, isolation, and continuous production of cytopathic retroviruses (HTLV-III) from patients with AIDS and pre-AIDS. Science. 1984;224:497-500.

51. Moreira-Ramos K, de Castro FM, Linhares-Lacerda L, Savino W. Can thymic epithelial cells be infected by human T-lymphotropic virus type 1? Mem Inst Oswaldo Cruz. 2011;106:759-62.

52. Ayres-Martins S, Lannes-Vieira J, Farias-De-Oliveira DA, Brito JM, Villa-Verde DM, Savino W. Phagocytic cells of the thymic reticulum interact with thymocytes via extracellular matrix ligands and receptors. Cell Immunol. 2004;229:21-30.

53. Giagnacovo M, Cardani R, Meola G, Pellicciari C, Malatesta M. Routinely frozen biopsies of human skeletal muscle are suitable for morphological and immunocytochemical analyses at transmission electron microscopy. Eur J Histochem. 2010;54:e31.

54. Sambro J, Fritsch EF, Mainatis T. Molecular cloning. Cold Spring harbour, NY: Cold Spring Harbour Laboratory Press; 1989.

55. Lepelletier Y, Smaniotto S, Hadj-Slimane R, Villa-Verde DM, Nogueira AC, Dardenne $M$, et al. Control of human thymocyte migration by Neuropilin-1/ Semaphorin-3A-mediated interactions. Proc Natl Acad Sci U S A. 2007;104:5545-50.

\section{Submit your next manuscript to BioMed Central and take full advantage of:}

- Convenient online submission

- Thorough peer review

- No space constraints or color figure charges

- Immediate publication on acceptance

- Inclusion in PubMed, CAS, Scopus and Google Scholar

- Research which is freely available for redistribution 